\title{
BMJ Open Key health outcomes for children and young people with neurodisability: qualitative research with young people and parents
}

\author{
Amanda Allard, ${ }^{1}$ Andrew Fellowes, ${ }^{1}$ Valerie Shilling, ${ }^{2}$ Astrid Janssens, ${ }^{2}$ \\ Bryony Beresford, ${ }^{3}$ Christopher Morris ${ }^{2}$
}

To cite: Allard A, Fellowes A, Shilling V, et al. Key health outcomes for children and young people with neurodisability: qualitative research with young people and parents. BMJ Open 2014;4:e004611. doi:10.1136/bmjopen-2013004611

- Prepublication history for this paper is available online. To view these files please visit the journal online (http://dx.doi.org/10.1136/ bmjopen-2013-004611)

Received 3 December 2013 Revised 24 March 2014 Accepted 27 March 2014

\section{CrossMark}

For numbered affiliations see end of article.

Correspondence to Dr Christopher Morris; christopher.morris@exeter.ac.uk
ABSTRACT

Objectives: To identify key health outcomes, beyond morbidity and mortality, regarded as important in children and young people with neurodisability, and their parents.

Design: Qualitative research incorporating a thematic analysis of the data supported by the Framework Approach; the International Classification of Functioning, Disability and Health (ICF) provided a theoretical foundation.

Setting: The study was conducted in community settings.

Participants: Participants were 54 children and young people with neurodisability: 50 participated in focus groups, and 4 in interviews; 53 parents participated: 47 in focus groups and 6 in interviews. Children/young people and parents were recruited through different networks, and were not related.

Results: Children/young people and parents viewed health outcomes as inter-related. Achievement in some outcomes appeared valued to the extent that it enabled or supported more valued domains of health. Health outcomes prioritised by both young people and parents were: communication, mobility, pain, self-care, temperament, interpersonal relationships and interactions, community and social life, emotional wellbeing and gaining independence/future aspirations.

Parents also highlighted their child's sleep, behaviour and/or safety.

Conclusions: Those responsible for health services for children/young people with neurodisability should take account of the aspects of health identified by families. The aspects of health identified in this study provide a basis for selecting appropriate health indicators and outcome measures.

\section{BACKGROUND}

Neurodisability describes a group of congenital or acquired long-term conditions that are attributed to impairment of the brain and/ or neuromuscular system and create functional limitations. ${ }^{1} \quad$ Neurodevelopmental

\section{Strengths and limitations of this study}

A methodological strength of this research was gathering the views of a wide range of participants, from socioeconomically diverse backgrounds, from different areas around England; a range of conditions was represented.

- The analytical coding framework was based on the International Classification of Functioning, Disability and Health: Children and Youth Version (ICF-CY), and also captured additional themes that were not classified in the ICF-CY.

- Our non-categorical analytical approach may have omitted any key outcomes that might be more specific and/or important for particular conditions.

conditions are the most common cause of disability, estimated to affect $3-4 \%$ of children in the UK. ${ }^{2}$ Children and young people with neurodisability are among the most frequent and intensive users of health services to manage symptoms (eg, seizures), and promote functioning and well-being.

In the UK health system, but probably salient elsewhere, there is recognition that families and health professionals do not always share a vision for what services are seeking to achieve, and efforts should be made to establish a shared focus. ${ }^{3}$ To achieve this, there is a need to consult families and professionals about key goals and outcomes to target. In the past, the voices of disabled children have often been overlooked, ${ }^{4}$ although it is recognised that they have both the right and desire to contribute their views. $^{5}$

Health services are increasingly focused on measuring outcomes, particularly those that reflect patients' priorities ${ }^{6}{ }^{7}$; such outcomes include routine data indicators, clinician assessments and patient and/or carer 
questionnaires. Outcomes of a health condition or injury can generally be considered within the WHO's International Classification of Functioning, Disability and Health (ICF). ${ }^{8}$ The ICF classifies components of health as 'body structures and functions' and 'activities' and 'participation'. In the context of neurodisability, it is often difficult for health services to make changes in 'body functions and structures', and there may be more scope for overcoming 'activity limitations' and/or 'participation restrictions'.

Evidence of the validity and reliability of health status measures is required. ${ }^{9}$ The constructs behind the stated 'outcomes' must be credible and perceived to be important to those using services, and also apt for the likely impacts of healthcare. Hence identifying a shared vision for the goals of health services and identifying key health outcomes to measure are inextricably linked.

In this qualitative study we sought to identify the key health outcomes, beyond morbidity and mortality, which are regarded as important to children and young people with neurodisability, and also separately to parents of such children. The study was part of research commissioned by the Department of Health in the UK that also included a Delphi survey with professionals and a systematic review of relevant patient reported outcome measures. ${ }^{10}$

\section{METHODS}

\section{Public and patient involvement}

The Peninsula Cerebra Research Unit involves families of disabled children as partners in research. ${ }^{11}$ One parent was involved with the application for funding. Including the parent who was a coapplicant, five parents volunteered to become involved. All were parents of children with neurodisability, including cerebral palsy, acquired brain injury or epilepsy syndrome. Parents worked alongside members of the research team at various stages of the research, including at team and parent advisory meetings. The group did not receive formal training for their involvement but were supported by members of the research team. Parents were offered $£ 25 /$ half day in acknowledgement of their time and contribution, and their travelling expenses were reimbursed. Their involvement included developing the topic guides and interpreting the findings; they are involved in disseminating findings.

\section{Recruitment and sampling}

The Council for Disabled Children (CDC) is the umbrella body for the disabled children's sector in England. Recruitment to the study was achieved through the use of pre-existing CDC networks. We used CDC's Making Ourselves Heard Network to engage children and young people, the Every Disabled Child Matters Campaign and the National Network of Parent Carer Forums to engage with parents of disabled children. The opportunity to take part in the research was advertised through these networks and on the CDC website. Both individuals and groups were able to volunteer. CDC then screened volunteers to ensure their eligibility with reference to an initial version of our definition of neurodisability. ${ }^{1}$

A two-stage approach to achieving the sample was used. The recruitment strategy and sampling for the focus groups was purposively arranged to capture diagnostic, demographic and geographic variation. The samples achieved for the focus groups were scrutinised and a subsequent round of interviewing used to address identified gaps in the sampling frame. For example, three interviews were arranged in a geographical region where insufficient parents had been recruited to run a focus group.

\section{Procedures for focus groups and interviews}

Most focus groups were held with groups that met regularly, and took place in venues that were familiar to the participants (eg, schools). Individual interviews were held at the participants' homes. Consent to take part was recorded, including from parents of participating children and young people; participants were also asked to provide demographic details about themselves and/ or their child. Different approaches were used to conduct interviews and focus group with children and parents.

\section{Groups/interviews with parents}

Parents working with the team had explored ways in which 'health outcomes' could be introduced and understood by participants in the context of this study. 'Outcomes' was perceived to be somewhat nebulous, and the term 'aspects of health' elicited more focused discussion and was preferred. The facilitator (AA) asked parents to imagine what improvements in their child's health they would hope for if health services were 'ideally' resourced and delivered. Then, in a second stage of the focus group or interview, the facilitator showed examples of four questionnaires commonly used to measure children's health (KIDSCREEN, PedsQL, Health Utility Index, EQ-5D-Y); both child-reported and parent/proxy-reported version were shown. Participants were asked about their initial impressions and whether they captured relevant outcomes.

\section{Groups/interviews with children and young people}

For children and young people our approach sought to depersonalise the topics we wanted to explore, and thereby encourage participants to discuss issues that they might otherwise be reluctant to reveal. An approach was piloted with an established disabled young people's group (led by AF, and observed by $\mathrm{CM}$ ). As with parents, we found that the concept of health outcomes was difficult for children and young people to grasp quickly. The pilot work led us to devise visual aids to facilitate and structure discussion to encourage a broader view and focus less on health 'problems'. 
Participants were presented with a picture (in A1 size poster format) of an imaginary young person affected by an unidentified health condition. They were invited to name the character and suggest possible health problems. The facilitator (AF) probed participants' views on: (1) what outcomes might be important to the character and (2) why these issues might be important in terms of the impact on the character's life, health and well-being. After the fourth focus group, three further posters were developed to facilitate more detailed discussions around the outcome areas emerging from the previous focus groups. These posters represented the following areas: physical health, mental and emotional health, and social and community issues. Specific prompts were used in these later focus groups (and all individual interviews) to stimulate more detailed discussion. Prompts explored participants' views on: (1) how the character in the poster might feel about each of the issues, (2) whether an issue was likely to be important to them and (3) what could be done to help improve the outcome. This structured conversation gave the participants the opportunity to explore and define the outcomes according to the importance they attached to them. After a break, participants were shown examples of the same questionnaires shown to the parents and asked about their acceptability, ease of completion and whether they captured relevant outcomes.

One of the groups comprised young people with communication impairment. For this group, an augmented approach was used, informed by issues and themes emerging from the focus groups that had already been carried out. The approach incorporated using a 'Talking Mat' to enable participants to indicate their preferences and priorities. ${ }^{12}$ Pictorial/symbol cards were produced to present information in an accessible format alongside simple verbal instructions. The facilitator (AF) collaborated with a speech and language therapist to create a primary set of 10 cards each representing a different health outcome. A further set of cards was also created to consider each health outcome in more detail.

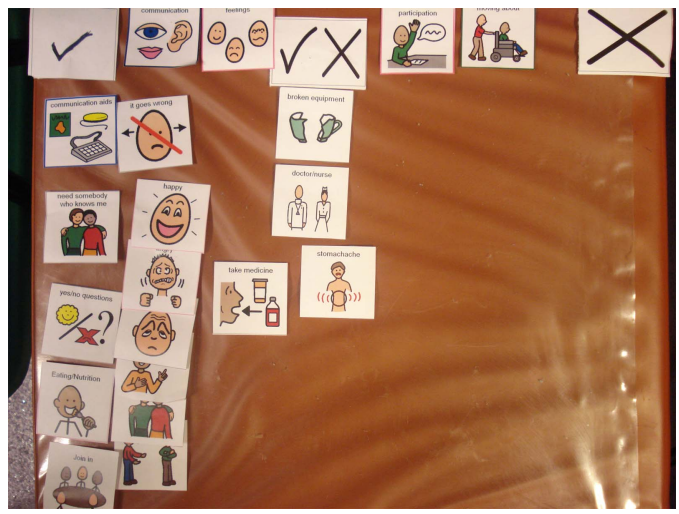

Figure 1 Example of Talking Mat Board used to enable young people with communication impairments to express their views.
First, working with a speech and language therapist the facilitator invited the participants to choose two to three cards that represented aspects of health that they wanted to prioritise, and the facilitator placed the selected cards on their board. Then, to explore a selected health issue, the secondary set of cards was used to probe their views and experiences in more detail. Participants were asked to indicate using the Talking Mat Board if, currently, each of these outcomes was something that was 'good', 'bad' or 'sometimes good and other times bad' for them, and the cards were placed appropriately on their Talking Mat. Participants were then asked which outcomes were 'more important', 'somewhat important' or 'not important' to them. These interactions were captured at key stages by photographing the boards with the cards positioned according to the participants' choices (figure 1).

All interviews and focus groups were audiorecorded, and completed Talking Mat Boards were photographed.

\section{Data management and analysis}

Audiorecordings were transcribed verbatim and transcripts checked by the interviewers.

NVivo10 software was used to manage and support data analysis.

A thematic analysis of the data supported by the Framework Approach was used for the analysis. ${ }^{13} 14$ Two researchers (AA/VS) read the transcripts from four focus groups and developed a thematic framework which captured data related to (1) children/young people's and parents' conceptualisations of health outcomes and their priorities around these outcomes; (2) responses to, and views about, existing standardised measures. The framework included a priori themes based on the ICF Children and Youth Version (ICF-CY) ${ }^{15}$ and additional themes emerging from the data.

The framework was then applied to the transcripts which were indexed by themes and subthemes using NVivo10. AA/VS separately indexed (coded) six transcripts to check for comprehensiveness and consistency indexing. Differences arising in interpretation between the researchers (indicated by disagreement between researchers higher than $2 \%$ and $\kappa$ lower than 0.40 ) were resolved through discussion. AA then coded all remaining materials from focus groups and interviews, working closely with the facilitator of the young people's groups and interviews $(\mathrm{AF})$. This was particularly important when coding material from the group where Talking Mats were used.

Indexed data were then summarised onto a series of thematic charts, one chart per theme/topic. The frequency and depth of discussion on a topic or theme was also recorded on the chart. The charts were divided into rows and columns. Relevant data from a data collection event (focus group, interview) were entered into a single row. Columns were used to categorise the data into subthemes.

Extensive analytical notes were written. At first these were used to create descriptive summaries of the data 
set out in the charts. Later analytical notes were used to develop and test conceptual ideas and to record and explore patterns and interconnections in the data. 'Mind-maps' were also used to display hypothesised relationships between health outcomes.

The emerging findings were discussed by the research team on a number of occasions, which helped to refine the analysis. The sample size was determined pragmatically, to enable a broad range of participants with different conditions and from different parts of England to be involved. The facilitators perceived no new issues were emerging when data collection ceased.

Where extracts of representative quotes are presented, the identification code focus group parents (FGP) is used for parents' focus groups, interview parent (IP) for parents' interviews, focus group children/young people (FGCY) for children and young people's focus groups, and IY for interviews with children and young people. For all extracts, square brackets containing three dots [...] indicate short sections of omitted speech. All names are aliases.

\section{RESULTS}

\section{Participants}

In total, 54 children and young people participated: 50 participated in focus groups, and 4 in interviews; 53 parents participated: 47 in focus groups and 6 in interviews (table 1). Participating children/young people and parents were not related, as they were recruited separately. There were six focus groups with children and young people that included between 4 and 10 participants (median 6.5), and six focus groups with parents that included between 6 and 11 participants (median 8.0). Generally parents were not present at the children/young people groups and interviews; however there were two focus groups in which a parent was in attendance to support one of their children.

Children/young people were aged 8-25 years (mean 16.5; SD 4.1). Parents indicated having between one and six children (mean 2.4; SD 1.07); the children of the parents were aged between 4 and 23 years (mean 11.6; SD 4.4). Ethnicity was mixed, although the majority who identified themselves were white British. There was variation by deprivation in the areas where participants lived. Several participants indicated more than one diagnosis; hence the 'primary' diagnosis shown in table 1 was a pragmatic judgement (by CM). In addition to the listed diagnoses, participating young people included seven who also had epilepsy and four who had sensory impairments. Some parents who took part had more than one child with a neurodisability: eight parents said they had two children and three parents had three children with neurodisability.

\section{Key outcomes}

Health outcomes identified and discussed by participants mapped closely on to many of the ICF domains
Table 1 Characteristics of participants

\begin{tabular}{|c|c|c|}
\hline & $\begin{array}{l}\text { Children/young } \\
\text { people }\end{array}$ & Parents \\
\hline \multicolumn{3}{|l|}{ Sex } \\
\hline Male/female & $34 / 20$ & $33 / 20$ \\
\hline \multicolumn{3}{|l|}{ Age of child } \\
\hline $\begin{array}{l}\text { Range (mean; SD) in } \\
\text { years }\end{array}$ & $8-25(16.5 ; 4.1)$ & $4-23(11.6 ; 4.4)$ \\
\hline \multicolumn{3}{|l|}{ IMD quintiles } \\
\hline $\begin{array}{l}1 \text { (less deprived } \\
\text { areas) }\end{array}$ & 7 & 8 \\
\hline 2 & 13 & 4 \\
\hline 3 & 9 & 2 \\
\hline 4 & 7 & 5 \\
\hline $\begin{array}{l}5 \text { (more deprived } \\
\text { areas) }\end{array}$ & 6 & 16 \\
\hline Missing & 12 & 18 \\
\hline \multicolumn{3}{|l|}{ Ethnicity } \\
\hline African & 0 & 2 \\
\hline African + white British & 1 & 1 \\
\hline Asian UK/Other & 1 & 1 \\
\hline Black UK & 0 & 2 \\
\hline Indian & 2 & 0 \\
\hline White British & 41 & 28 \\
\hline White Irish & 0 & 2 \\
\hline White Irish + Brazilian & 0 & 1 \\
\hline White other & 2 & 0 \\
\hline Other (not detailed) & 0 & 2 \\
\hline Missing & 7 & 14 \\
\hline \multicolumn{3}{|l|}{ Neurological diagnosis } \\
\hline Acquired brain injury & 0 & 2 \\
\hline ADHD & 1 & 0 \\
\hline ADHD/ASD & 0 & 1 \\
\hline ASD & 16 & 13 \\
\hline Awaiting diagnosis & 2 & 0 \\
\hline Cerebral palsy & 9 & 18 \\
\hline Developmental delay & 1 & 3 \\
\hline Down syndrome & 1 & 6 \\
\hline $\begin{array}{l}\text { Duchene muscular } \\
\text { dystrophy }\end{array}$ & 5 & 0 \\
\hline Learning disability & 3 & 4 \\
\hline Syndrome & 6 & 5 \\
\hline Missing & 10 & 1 \\
\hline \multicolumn{3}{|l|}{ DLA CC) } \\
\hline Higher rate & 16 & 36 \\
\hline Middle rate & 10 & 11 \\
\hline Lower rate & 3 & 0 \\
\hline None & 2 & 0 \\
\hline Missing & 23 & 6 \\
\hline \multicolumn{3}{|l|}{ DLA MC } \\
\hline Higher rate & 16 & 29 \\
\hline Lower rate & 9 & 18 \\
\hline None & 2 & 0 \\
\hline Missing & 27 & 10 \\
\hline
\end{tabular}

ADHD, attention-deficit hyperactivity disorder; ASD, autistic spectrum disorder; DLA CC, disability living allowance care component; DLA MC, disability living allowance mobility component; IMD, Index of Multiple Deprivation 2010 (a measure of deprivation experienced by people living in an area). 
Table 2 Health outcomes highlighted by children, young people and parents mapped to domains of the ICF-CY

\begin{tabular}{ll}
\hline ICF domain & Example areas \\
\hline Communication & Using language, signs and symbols \\
Mobility & Moving around, changing location \\
Sensory functions & Hearing, seeing \\
Pain & General or localised discomfort \\
Sleep & Onset and quality of sleep \\
Interpersonal interactions and relationships & Friends and family \\
Making decisions and choices & Preferences \\
Neuromusculoskeletal and movement-related functions & Gait, moving limbs \\
Self-care & Diet, exercise, washing, dressing and toileting \\
Major life areas & Education, work \\
Functions of cardio and respiratory systems & Endurance and fatigue \\
Community and social life & Recreation, sports and leisure \\
Other mental functions & Consciousness, orientation, social skills, cognition, energy and drive \\
Temperament & Behaviour, mood, emotion, anxiety, attention and concentration \\
Body structures & \\
Genitourinary and reproductive functions & Continence, enuresis \\
Functions of digestive system & Constipation, swallowing, drooling \\
\hline ICF, International Classification of Functioning Disability and Health; ICF-CY, ICF Children and Youth Version.
\end{tabular}

(table 2). Two additional themes in the data not covered by the ICF were 'emotional wellbeing' and 'gaining independence/future aspirations'.

\section{Relationships between outcomes}

It was evident throughout the narratives that children, young people and parents did not view health outcomes as a set of independent, stand-alone constructs. Rather, they viewed outcomes as inter-related, facilitating or inhibiting each other. Health outcomes were almost always spoken of in terms of whether they impacted on, or were impacted by, other aspects of health, and the overall impact this had on their lives and experiences.

The research team analysed how the participants connected various health outcomes, and mapped the nature of interactions and inter-relationships (eg, figures 2 and 3 for 'community and social life'). We perceive a hierarchical relationship between the different aspects of health: some outcomes appeared to be valued as much for their ability to facilitate or contribute to the achievement of other desired outcomes than necessarily as an endpoint in themselves. For example, poorly managed pain would impact on the extent of attainment in other aspects of the child's life, such as learning or participation in social activities. However, achieving higher level outcomes is not necessarily dependent on the achievement (in part or full) of all of the lower level outcomes.

Aspects of health coded to the ICF domains for body structures and functions were the more 'facilitative' aspects of health (figures 4 and 5). 'Intermediary' outcomes included communication, mobility, making choices, learning and applying knowledge. 'Higher-level' outcomes included those which were less overtly connected to physical and mental health functions, such as social participation and friendships, but within which parents and young people clearly identified as a component of health. Higher-level outcomes identified both by parents and young people were emotional wellbeing and social and community life. Parents also prioritised their children gaining greater independence, while children/young people emphasised more their interpersonal interactions and relationships (friends and family).

Huge differences in terms of Daisy being able to make clear choices, having key words to be able to slow herself down without the anxiety building up to her thumping somebody [...] Huge differences in terms of her whole wellbeing, her mental health and wellbeing. [...] she is now living a life that's having fun and doing things [... but the most important thing, she's relaxed and you can physically see that with her. (FGP6)

Key outcomes emerged to which participants seemed to ascribe more value; generally, this was because of the extent to which it was felt that they enabled disabled children and young people to live an ordinary and fulfilled life. The key outcomes included communication, mobility, pain, self-care, temperament, relationships, social life, emotional well-being and developing independence.

Each of these domains is described in more detail in the sections below. We would note, however, the relative value and importance of different outcomes was not identified in terms of the frequency of which outcomes were mentioned. Rather, we report parents' and young people's views of relative importance, and the reasons behind their priorities.

\section{Communication}

Communication was regarded as highly important because it was fundamental to making choices, decision-making, independence and social interaction. Being in settings or situations where young people were not able to communicate was 


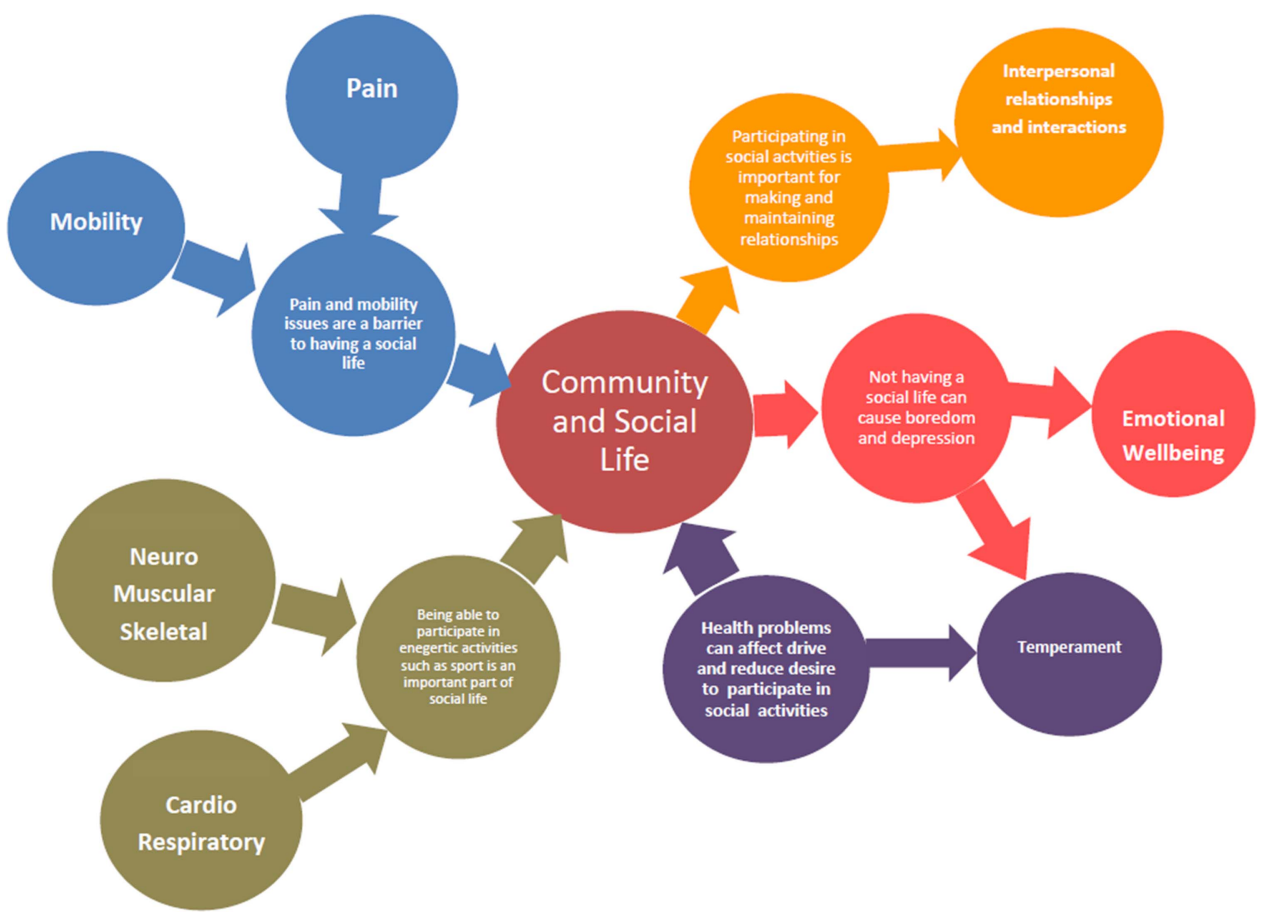

Figure 2 Our mapping of children/young people's perceptions of how 'Community and social life' is related to other aspects of health.

a source of anxiety, associated with fears of people taking decisions without taking their preferences into account:

It's easy for someone to decide for you, but they don't really know how you feel about, you know, what you want or need [...] I think if the other person can't communicate then what they want might not get done. (FGCY2)

The only person that can tell people about it is yourself really, isn't it? (interview children/young people (ICY); ICY4)

Some parents identified a link between communication difficulties, or a lack of others' understanding of their child's method of communication, and safety issues and/or challenging behaviour. Parents were also more confident about their children managing when they were not present if their children were able to communicate their own needs and preferences.

And he can't tell us if he's feeling depressed or angry or, he can scream and wave his arms around and that's how we know something's not quite right. (FGP2)

And they can make choices. [...] Teach them to say yes or no [...] Just a big thing is yes and no. It's a huge thing is yes or no. (FGP1)

\section{Mobility}

Children and young people closely associated mobility with being able to go where they wanted in order to access social and community activities, attend school, take part in sporting activities and keep up with non- disabled peers. For wheelchair users, their mobility equipment was more important to them than their physical functioning, that is, their ability to stand or walk (figure 1).

Being able to move when you want to move and not when other people just want to move you, as well, so you've got a choice over where you're going and what you're doing. (FGCY2)

I was just going to say like having mobility aids can be, help give you more a sense of freedom and independence to move around and to do more what you please.

(FGCY2)

Parents were concerned about the impact of mobility limitations on social relationships and interaction, most commonly in relation to play. Parents also highlighted situations where children's learning disability created concerns about them being safely mobile:

It's not that they're being mean, but they don't play with Dan, because he can't, so they end up getting too busy and zooming off somewhere else, and he feels that a lot, I think. (IP6)

If she sees something she fancies. She ran out of the house and she stopped a taxi in the road, and she lay on its bonnet and was shouting ow, ow. She'd seen something on the telly. (FGP3) 


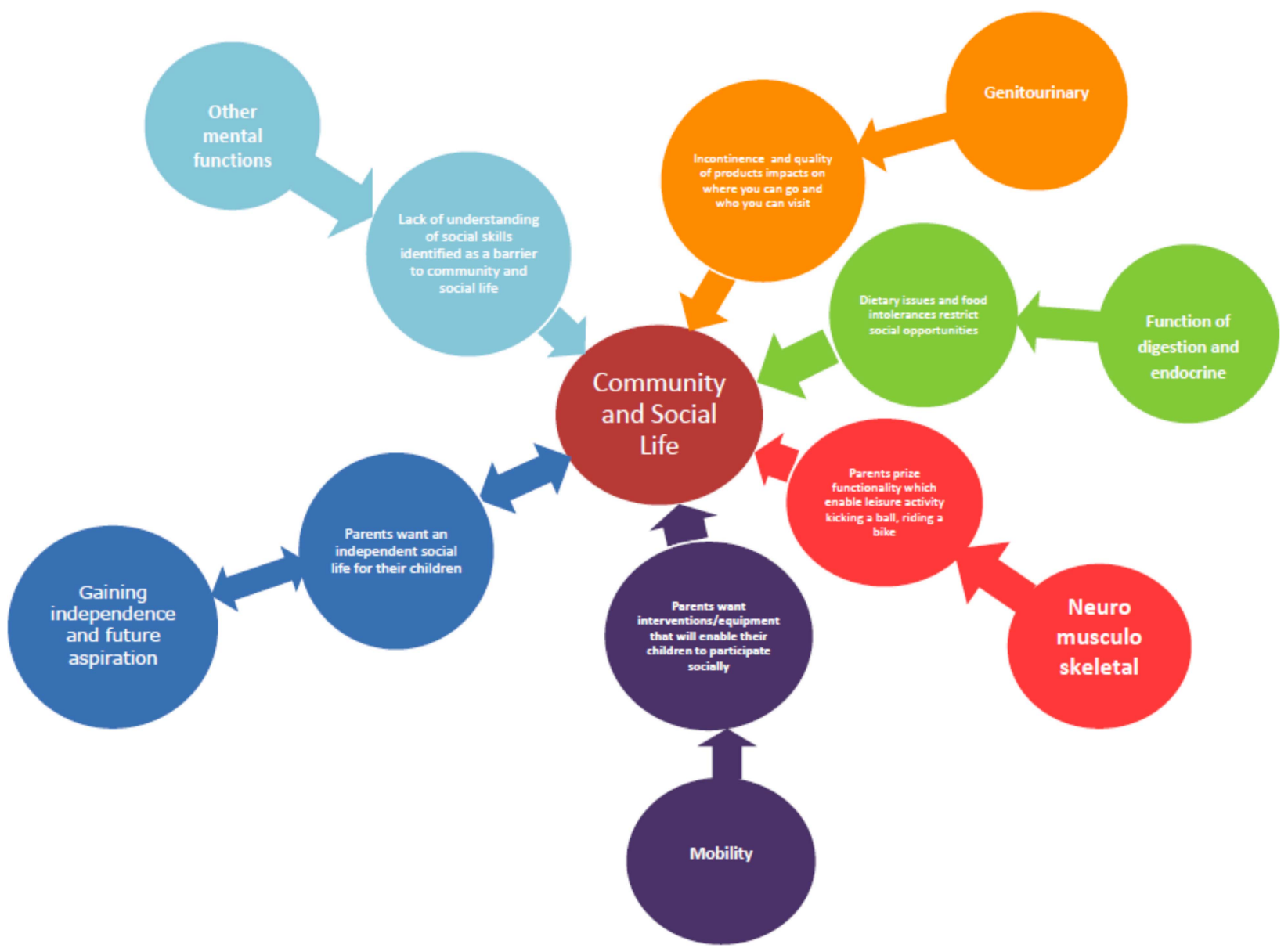

Figure 3 Our mapping of parents' perceptions of how 'Community and social life' is related to other aspects of health.

Pain

Children and young people identified pain as a source of physical discomfort and also a major barrier to achievements or experiences in many other life domains. It was something that affected 'everything' (FGCY1 and ICY4). For example, the children and young people described how pain impacted on school attendance, and participation at school, both academically and socially.

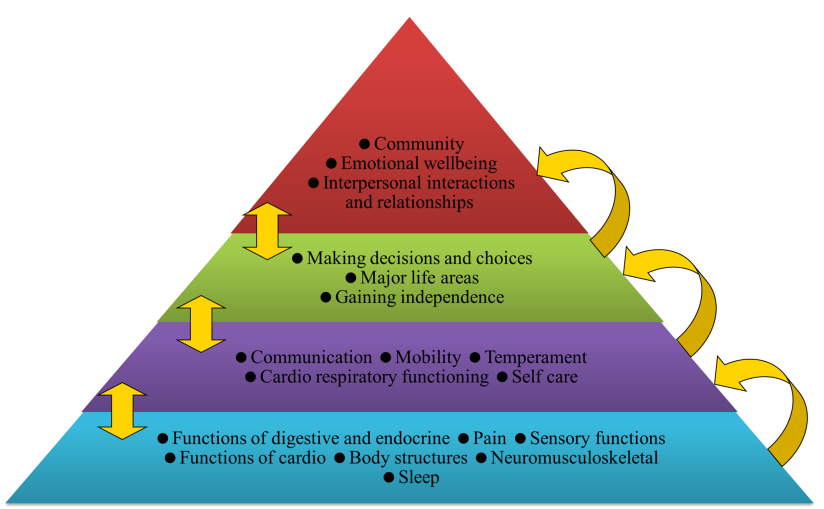

Figure 4 Illustrative hierarchy of inter-relationships between aspects of health as perceived by children/young people.
If you're in a lot of pain then, and that's not being managed properly, then it's going to affect what you can and can't do as well, and whether you can enjoy doing those things, concentration and things like that. (ICY3)

Wheelchair users discussed the importance of being able to minimise discomfort resulting from long periods of sitting in one position, and reducing the risk of pressure sores. Poorly fitting or uncomfortable mobility aids

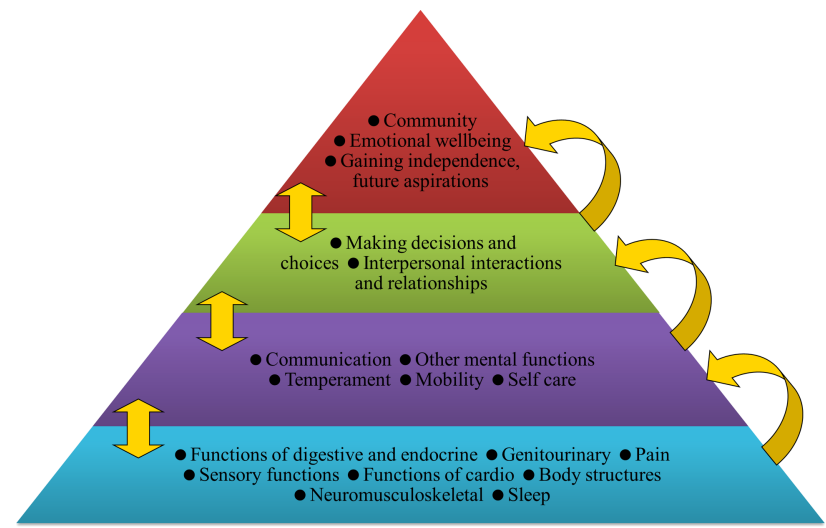

Figure 5 Illustrative hierarchy of inter-relationships between aspects of health as perceived by parents. 
were a barrier to mobility. Parents were also concerned about pain caused by poorly designed equipment.

If you have splints or orthotics on your legs it's just making sure they fit properly otherwise that can cause quite a lot of pain. (FGCY4)

The nappies that we've got keep him dry. [...] He obviously still has the soreness issue. So it would be nice to have some $[\ldots]$ where they've got the layer that protects the skin. It just seems to be basic. (IP5)

\section{Self-care}

Independence in terms of self-care was discussed more frequently by parents than young people. For example, some parents rated independent toileting as a key health outcome. They were disappointed when health services did not support self-care skills; for instance when 'pull up' nappies were not provided. Self-care was seen as critical to gaining independence and parents often talked about the two concepts in tandem.

Daniel nowadays he loves his independence when he can shower himself and wash himself, but at the moment I have to supervise him. (FGP3)

For children and young people, their ability to carry out self-care independently was linked to fatigue and/or pain.

They become tired and it makes it very difficult, like for instance going to the toilet, getting yourself dressed if your legs, if you try to do any little things then it can hurt and become all of a sudden very difficult. (FGCY8)

\section{Temperament}

We used the term temperament to include references to behaviour, mood, anxiety and concentration, and the ability to control these areas. These topics featured more strongly for parents than for children and young people. Some children and young people described being unable to control emotions such as anger and frustration resulting in verbal or physical outbursts that impacted on their relationships.

At school when people annoy me, I get really frustrated. I get really annoyed, and I shout at them, and there's no need for me to shout at them, and I just need to calm down...because then people would think that I'm a better friend. (FGCY1)

Parents frequently expressed reducing their children's frustration, challenging behaviour and/or anxiety as desired outcomes. Parents noted the association between these issues and other aspects of their child's life. For example, anxiety impacted on sleep quality, and anxiety and challenging behaviour were barriers to learning and forming relationships. Communication difficulties were cited commonly as the reason behind behavioural issues.
We've had problems with him kicking out and being frustrated and knocking teachers to the ground and just being really, really cross and it's because he's, somebody can't understand him. (FGP1)

\section{Interpersonal relationships and interactions}

Having positive relationships with peers, friends and family was viewed as a key part of life. Again, connections were made between this and other outcome areas. Children and young people described friendships as crucial for maintaining good mental health and positive emotional well-being:

If you don't play with your friends you lose them, but if you see your mates you're more than happy. (FGCY1)

If you don't have a group of friends at school, then you're a bit like 'what's the point of living?' (FGCY2)

Parents were often concerned about quality or extent of their child's friendships and social networks. They described situations where their children were left behind, not included, or bullied. Parents recognised that challenging behaviour and anxiety were potential barriers to forming successful relationships.

\section{Community and social life}

Children, young people and parents rated community and social life, such as opportunities to be involved in recreation and leisure activities, as a key aspect of social inclusion. Children and young people's desire to be included within their community was articulated particularly with respect to participation in sports.

I think it, having a social life could impact on your health as well because if you've got one and able to go out and see friends and family members or anyone ... So you'll feel happy in yourself and sometimes being happy and being with people you know and going out, it can benefit it on your health. So I think it's really important that all disabled people should have some sort of social life because it can have a positive effect and sometimes even improve your health. (FGCY4)

The value placed on participating in community life was closely related to the importance of friendships and relationships with family. Parents articulated its fundamental role in enjoying life. However, many parents also described community-based activities and settings from which they were excluded.

But the fact she is now living a life that's having fun and doing things and taking part in theatre productions and all sorts of stuff. (FGP6)

He's becoming part of the community, which is what I really wanted for him [...] he goes [to his local pub] and he gets his Coke and his packet of cheese and onion crisps, and they have it on the bar waiting for him now. Hello [son's name], how are you? And it's, it's what I 
want for him when he's older, they'll know him, and when I'm long gone, he'll be part of something, he'll have people that know him and that can chat to him and say hello. (IP6)

\section{Emotional well-being}

Children and young people identified feeling happy, sociable and relaxed as positive indicators of their emotional well-being. Anxiety, depression and frustration were cited as negative. They frequently used reference to their emotional well-being to explain why other outcomes were important to them.

They'd get in a lot more pain, more frustrated and all that. And they wouldn't be happy either. (ICY1)

It would make you depressed because you wouldn't be able to make any friends. (FGCY4)

I think it might affect other things as well, how happy you are as a person. (ICY3)

Emotional well-being was also a strong theme in parents' discussions about their aspirations for their child's life. Indeed they often prioritised emotional wellbeing over other outcomes.

My main objective is to make sure he's happy and he's comfortable. (IP4)

I just want him to be happy. (IP6)

Parents identified aspects of well-being not expressed by the children and young people. Specifically, they wanted their children to feel good about themselves, to have a positive self-image and to be able to value their strengths.

\section{Gaining independence, future aspirations}

Parents wanted their children to reach their maximum potential. They wanted their children to be the best they could be, whatever that might mean. Therefore, they valued interventions that increased their children's independence and supported them to achieve their potential. Being independent in self-care and being able to communicate, were concepts most frequently referred to in relation to gaining independence. Parents cited low expectations from others as barriers to their child maximising their independence.

The last time we saw [a speech and language therapist] she just turned round and said, 'Liam's Liam'. That doesn't help me. [...] I hate that [...] what does that mean 'Liam's Liam'? [...] it's low expectation. (FGP5)

Children and young people made indirect references to independence and their aspirations. They were certainly concerned with being able to make choices and participate in activities independently, but this was expressed in the present or near future, rather than as longer term aspirations.

\section{DISCUSSION}

In this qualitative study we sought to identify key health outcomes for children and young people with neurodisability. This, perhaps, proved more complicated than we had anticipated, as participants viewed outcomes as interrelated.

Our interpretation of the data suggests to us that the relationship between health outcomes may be represented as a hierarchy. With some outcomes, such as pain control, acting as facilitators that contribute to the achievement of higher level outcomes, such as gaining independence. Achieving higher level outcomes is not dependent on the achievement (in part or full) of all of the lower level outcomes. Different outcomes in each layer will have different relevance and value to different families based on how it contributes to achieving other desired life goals. We represent the hierarchy as we perceive it for illustrative purposes (figures 4 and 5), although these should not necessarily be viewed as definitive.

Higher level outcomes prioritised by young people and parents were emotional well-being and involvement in community and social life. Children and young people also indicated interpersonal relationships and interactions (with friends and family as most important); in contrast, children gaining independence appeared to be a more important outcome for parents.

Health outcomes highlighted most frequently by children, young people and parents were: communication, mobility, pain, self-care, temperament, interpersonal relationships and interactions, community and social life, emotional well-being, and gaining independence. In addition, discussions with parents revealed that sleep, toileting and safety (which were included in the self-care and gaining independence domains) were particularly valued. Other aspects of health in our coding framework (including many areas of body functions and structures) were mentioned, but less frequently.

Differences between children and young people and parents' priorities in terms of health outcomes are not unexpected. They can partly be ascribed to differing personal perspectives, lived experiences and social roles. For instance, children and young people described pain as impacting on many areas of life, whereas for parents pain was something that needed to be managed but they identified fewer associations with other aspects of health. Conversely, independence and self-care, sleep, toileting and safety is likely to reflect parents' roles as carers. The characteristics of the participating children/ young people and parents in our study may explain some variance in the issues raised. Children with impairments that precluded their involvement were not represented in our sample; whereas parents of such children did participate. 
A methodological strength of this research was gathering the views of a wide range of young people and parents. Research participants were drawn from socioeconomically diverse backgrounds, from different areas around England, and a range of conditions was represented. We were also successful in including children and young people who did not use speech to communicate. Nevertheless, although a broad range of conditions was represented, the sampling could not capture all conditions under the umbrella of neurodisability. Our analytical approach was non-categorical, so we did not seek to map whether views had links to particular diagnoses in any systematic way, and for this reason we felt justified in coding focus group data as group units. This may impact on the omission of any key outcomes that might be more specific and/or important for particular conditions; there may be different priorities for subgroups of children and young people. However, our findings accord closely with health priorities identified in research with children and young people with complex healthcare needs, those who do not use speech for communication, autism and cerebral palsy. ${ }^{16-18}$ We found coding using the ICF to be useful in the context of this research, although we also found that some key concepts were not classifiable using the system.

A major challenge was that many of our participants found the concept of health outcomes to be somewhat nebulous. Hence, in consultation with parents working in partnership with the researchers, we tended towards using prompts that presented them with outcome areas and examples of patient reported outcome measure questionnaires. This approach may have influenced the scope of the ideas that participants generated. Nevertheless, our approach was largely successful in enabling us to address the research objective. The involvement of parents was a vital influence on the design and interpretation of this research. Reflecting on our public and patient involvement, it would have been desirable to involve young people. However, to achieve this meaningfully would have required considerable planning and resources to find interested young people, and then support them throughout their involvement. There remains much scope for methodological research to inform appropriate approaches to public and patient involvement in childhood disability research.

The outcomes that children, young people and parents perceive to be most important to their health and well-being provide valuable information for clinicians, service commissioners and policymakers. Identifying these health outcomes is an incremental step towards developing a vision of what health services should seek to achieve. In parallel to this work, we explored what health professionals are seeking to achieve and also reviewed relevant available patient reported outcomes measures (PROM) questionnaires; details of these studies are available in the National Institute for Health Research (NIHR) Library. ${ }^{19}$
Author affiliations

${ }^{1}$ Council for Disabled Children, National Children's Bureau, London, UK

${ }^{2}$ Peninsula Cerebra Research Unit (PenCRU) \& PenCLAHRC, University of Exeter Medical School, Exeter, UK

${ }^{3}$ Social Policy Research Unit, University of York, York, UK

Acknowledgements The authors are grateful to the parents who were involved with us as partners in the research and our co-investigators in the broader study. This paper is part of a report published by the National Institute for Health Research Library (Project 10/2002/16). Where possible, we have made substantial changes to avoid direct duplication, however, some content remains the same.

Contributors All the authors made substantive contributions and were involved in the conception and design, acquisition of the data, and analysis and interpretation of the data; in drafting the article or revising it critically for important intellectual content; and approved the version of the manuscript submitted.

Funding This study was part of research funded by the National Institute for Health Research (NIHR) Health Services and Delivery Research programme (Project 10/2002/16 http://www.nets.nihr.ac.uk/projects/hsdr/10200216). The work also benefited support from NIHR Collaboration for Leadership in Applied Health Research and Care of the South West Peninsula (PenCLAHRC), and the charity Cerebra. The views and opinions expressed in this paper are those of the authors and not necessarily those of the NHS, the NIHR, the Department of Health, or Cerebra.

Competing interests None.

Ethics approval The UK National Research Ethics Committee North EastCounty Durham and Tees Valley approved the procedures for the study (reference 11/NE/0364).

Provenance and peer review Not commissioned; externally peer reviewed.

Data sharing statement Further data is available in the full report available through the NIHR Library, or by contacting the corresponding author.

Open Access This is an Open Access article distributed in accordance with the Creative Commons Attribution Non Commercial (CC BY-NC 3.0) license, which permits others to distribute, remix, adapt, build upon this work noncommercially, and license their derivative works on different terms, provided the original work is properly cited and the use is non-commercial. See: http:// creativecommons.org/licenses/by-nc/3.0/

\section{REFERENCES}

1. Morris C, Janssens A, Tomlinson R, et al. Towards a definition of neurodisability: a Delphi survey. Dev Med Child Neurol 2013;55:1103-8.

2. Emerson E. Deprivation, ethnicity and the prevalence of intellectual and developmental disabilities. J Epidemiol Community Health 2012;66:218-44.

3. Kennedy I. Getting it right for children and young people: overcoming cultural barriers in the NHS so as to meet their needs. Department of Health, 2010.

4. Hallet $\mathrm{C}$, Prout $\mathrm{A}$, eds. Hearing the voices of children: social policy for a new century. Routledge, 2003.

5. Department of Health. Our Children Deserve Better. Annual Report of the Chief Medical Officer. 2012.

6. Department of Health. The NHS Outcomes Framework 2011/12.

7. Fitzpatrick R. Patient-reported outcome measures and performance measurement. In: Smith PC, Mossialos E, Papanicolas I, Leatherman S, eds. Performance measurement for health system improvement: experiences, challenges and prospects. Cambridge University 1134 Press, 2009.

8. World Health Organisation. International classification of functioning, disability and health. Geneva, Switzerland: WHO, 2001.

9. Streiner DL, Norman GR. Health measurement scales: a practical guide to their development and use. Oxford University Press, 2008

10. Morris C, Shilling V, Allard A, et al. Informing the NHS Outcomes Framework: what outcomes of NHS care should be measured for children with neurodisability? NIHR Health Services Research Programme. 2011. http://www.netscc.ac.uk/hsdr/projdetails.php? ref $=10-2002-16$ (accessed 8 Sep 2013). 
11. Morris C, Shilling V, McHugh C, et al. Why it is crucial to involve families in all stages of childhood disability research. Dev Med Child Neurol 2011;53:769-71.

12. Murphy J, Cameron L. The effectiveness of Talking Mats for people with intellectual disability. Br J Learn Disabil 2008;36: $232-41$.

13. Ritchie J, Spencer L. Qualitative data analysis for applied policy research. In: Bryman A, Burgess R, eds. Analyzing qualitative data. Routledge, 1994

14. Pope C, Ziebland S, Mays N. Qualitative research in health care. Analysing qualitative data. BMJ 2000;320:114-16.

15. World Health Organisation. International classification of functioning, disability and health: version for children and youth. Geneva, Switzerland: WHO, 2008
16. Rabiee P, Sloper P, Beresford B. Desired outcomes for children and young people with complex health care needs, and children who do not use speech for communication. Health Soc Care Community 2005;13:478-87.

17. Beresford B, Tozer R, Rabiee $\mathrm{P}$, et al. Desired outcomes for children and adolescents with autistic spectrum disorders. Child Soc 2007;21:4-16.

18. Young B, Rice H, Dixon-Woods M, et al. A qualitative study of the health-related quality of life of disabled children. Dev Med Child Neurol 2007;49:660-5.

19. Morris C, Janssens A, Allard A, et al. Informing the NHS Outcomes Framework: what outcomes of NHS care should be measured for children with neurodisability? Health Serv Deliv Res (In press) 2014. http://www.nets.nihr.ac.uk/projects/hsdr/10200216 